\title{
ETNOASTRONOMIA E ASTROBIOLOGIA CULTURAL: ICONOGRAFIA ZOOMÓRFICA DAS CONSTELAÇÕES INDÍGENAS BRASILEIRAS
}

\section{ETHNOASTRONOMY AND CULTURAL ASTROBIOLOGY: ZOOMORPHIC ICONOGRAPHY OF BRAZILIAN INDIGENOUS CONSTELLATIONS}

Amanda Hellen Sales Gonçalves ${ }^{1}$, Bruno Leonardo do Nascimento Dias², Francielle Maria Antonio Silva ${ }^{3}$

\author{
Submetido: 04/03/2021 \\ Aprovado: 10/03/2021
}

\section{RESUMO}

A etnoastronomia investiga o conhecimento astronômico de povos tradicionais atuais por meio de registros históricos etnográficos. Dentre esses registros, o presente trabalho possui como principal objetivo apresentar as constelações indígenas brasileiras que possuem iconografia zoomórfica atreladas à natureza, ao ambiente e à cultura regional pouco conhecidas. Com base nos resultados obtidos foi possível concluir que, tal como ocorre com a Astronomia oriunda da mitologia grega, a Astronomia indígena também possui conotações e detalhamentos riquíssimos relacionados não apenas as questões mitológicas, mas com base nas flutuações sazonais indicadas pelas constelações os povos indígenas brasileiros demarcavam o período da pesca, caça, plantio e colheita. Assim, espera-se que este trabalho ajude a popularizar, fomentar o respeito e a valorização da identidade cultural dos povos indígenas brasileiros.

PALAVRAS-CHAVES: Astronomia. Zoocultura. Mitologias

\begin{abstract}
Ethnoastronomy investigates the astronomical knowledge of today's traditional peoples through historiographical records. Among these records, the present work has as main objective to present the Brazilian indigenous constellations that have zoomorphic iconography linked to nature, the environment and the regional culture little known. Based on the results obtained, it was possible to conclude that, as with Astronomy from Greek mythology, indigenous Astronomy also has very rich connotations and details related not only to mythological issues, but based on the seasonal fluctuations indicated by the constellations of Brazilian indigenous peoples demarcated the period of fishing, hunting, planting and harvesting. Thus, it is hoped that this work will help to popularize, foster the respect and appreciation of the cultural identity of Brazilian indigenous peoples.
\end{abstract}

KEYWORDS: Astronomy. Zooculture. Mythological

\footnotetext{
1 Licenciatura em Ciências Biológicas na Universidade Estadual do Rio de Janeiro pelo Cederj/Cecierj.https://orcid.org/0000-0003-1870-3807 - amandahellen.bio @gmail.com

2 Licenciatura em Física pela FTESM com graduação sanduíche em Bachelor of Science na Monash University em Melbourne na Austrália. Mestrado em Física pela UERJ e Doutorado em Física pela UFJF com ênfase em Astrobiologia - https://orcid.org/0000-0002-3632-9073 - bruno.astrobio@gmail.com

3 Cursando bacharel em Astronomia no Observatório do Valongo da UFRJ - francielle19@astro.ufrj.br
} 


\title{
RECIMA21 - REVISTA CIENTÍFICA MULTIDISCIPLINAR
}

\author{
ETNOASTRONOMIA E ASTROBIOLOGIA CULTURAL: ICONOGRAFIA ZOOMÓRFICA \\ DAS CONSTELACÕES INDÍGENAS BRASILEIRAS \\ Amanda Hellen Sales Gonçalves, Bruno Leonardo do Nascimento Dias, Francielle Maria Antonio Silva
}

\section{Introdução}

Desde os tempos mais primórdios os nossos antepassados já possuíam o costume de observar o céu, mesmo antes da astronomia e objetos mais sofisticados surgirem (TOLMASQUIM, 2013). Cosmogonias foram construídas por inúmeras civilizações antigas que interpretavam os astros como divindades, criando as primeiras constelações a partir dos astros que pontuam e cruzam o céu (AFONSO e NADAL, 2013). Vale salientar que essa curiosidade por contemplar algo tão imensurável foi responsável por muitas das culturas e ciências que temos hoje.

Com a identificação de padrões para predizer as estações do ano, bem como as melhores épocas para o plantio e colheita, o estudo dos astros possibilitou grandes avanços para a humanidade. De acordo com GALDINO (2011), ainda na pré-história o homem já teria sido capaz de perceber que as variações climáticas, produção de frutos e o processo de reprodução dos animais estavam relacionados com as diferentes estações do ano. Dessa forma, com base nesses ciclos observados na natureza, o ser humano começaria a relacionar esses processos à sua volta com os ciclos de estrelas no céu através das constelações.

Da mesma forma como a observação do céu tem ajudado a moldar o pensamento humano, as concepções filosóficas também influenciam na forma de olhar o espaço celeste e os vários elementos que o compõem (TOLMASQUIM, 2013). De acordo com o local e o povo há interpretações culturais desenvolvidas de modos e usos diferentes (PEDRA e CHAVES, 2017; ROSSETI, 2003). Assim, nosso foco será a cultura brasileira e a astronomia indígena que possui interpretações e aplicações muito singulares.

Os povos indígenas apenas com o entendimento vindo de observar o céu, conseguiam determinar pontos (estrelas) no céu para marcar a orientação do tempo e do clima (AFONSO, 2009). Desse modo, os índios brasileiros foram capazes de associar o melhor tempo para se realizar o desenvolvimento da agricultura local através da divisão de estações do ano que estavam associadas ao ciclo de constelações no céu (AFONSO, 2010).

Um dos pioneiros a documentar, descrever e manter viva a história da cultura indígena brasileira foi o missionário capuchinho francês Claude d'Abbeville, que em 1612, passou quatro meses com os Tupinambá do Maranhão, perto da Linha do Equador (LIMA, 2004 e AFONSO, 2013). No seu livro Histoire de la Mission de Pères Capucins en l'Isle de Maragnan et terres circonvoisins, publicado em Paris, em 1614, considerado uma das mais importantes fontes da etnografia dos Tupi, 


\title{
RECIMA21 - REVISTA CIENTÍFICA MULTIDISCIPLINAR
}

\author{
ETNOASTRONOMIA E ASTROBIOLOGIA CULTURAL: ICONOGRAFIA ZOOMÓRFICA \\ DAS CONSTELACÕES INDÍGENAS BRASILEIRAS \\ Amanda Hellen Sales Gonçalves, Bruno Leonardo do Nascimento Dias, Francielle Maria Antonio Silva
}

conforme CORRÊA e SIMÕES (2016), o francês Claude d'Abbeville registrou o nome de cerca de 30 estrelas e constelações conhecidas pelos índios da ilha. Assim, o objetivo principal deste trabalho relativo a zoologia cultural será apresentar a partir de um contexto etnoastronômico todas as constelações indígenas que possuem animais.

\section{Material e métodos}

Para este artigo foram analisadas as informações da astronomia cultural dos povos Tupi e Guarani. Segundo MIRANDA (2019), os estudos historiográficos informam que os povos indígenas buscam compreender e interpretar o mundo em que vivem realizando observações sobre a natureza, o firmamento e, inclusive, fazendo registros astronômicos de estrelas que passaram a ter conotações culturais regionais. Os índios brasileiros deram atenção especial aos astros: Sol, Lua, Vênus e as estrelas do céu mapeando-as por meio de constelações. É importante destacar que os responsáveis por nomear e desenhar as constelações no céu eram os pajés das tribos, que assimilavam o que viam no céu com o ambiente que era visto a sua volta, e daí davam a nomenclatura da constelação a partir de animais da região, por exemplo.

Em particular, o presente trabalho se desenvolverá com base nas estrelas que formam constelações para os povos indígenas brasileiros. Dentre as constelações indígenas foi escolhido como foco principal todas aquelas que possuem iconografia zoomórfica. O intuito desta escolha é mostrar que em aulas de Mastozoologia, Herpetologia, Entomologia e Ornitologia é possível fazer associações culturais e mostrar que existem contextos de alguns animais destas áreas que poderiam despertar curiosidades por meio da representação de alguns deles como constelações do céu indígena, inclusive, uma cultura nacional pouco difundida. Vale salientar que constelações que não representam figuras de seres zoomorfos não serão apresentadas e mencionadas aqui.

Grande parte dos resultados que serão apresentados foram retirados de textos, artigos e matérias em jornais oriundos de pesquisas feitas por Germano Afonso, que é um astrônomo que atua na Amazônia e grande responsável pelo resgate de muitas informações sobre a cultura indígena brasileira atualmente. Infelizmente, essa cultura nos dias de hoje tem sido negligenciada por nós que fazemos parte do povo brasileiro e até mesmo pelos próprios índios do Brasil.

O método de desenvolvimento descritivo neste trabalho parte dos conceitos investigativos da etnoastronomia. A etnoastronomia investiga o conhecimento astronômico de povos tradicionais atuais, ou seja, cultura contemporânea por meio de registros etnográficos e relatos de tradições orais (AFONSO, 2010). Todos os dados foram coletados através de pesquisas disponibilizadas abertamente em livros, artigos e materiais historiográficos que possuíam informações da área de etnoastronomia, em particular, da cultura indígena brasileira. Para maior acessibilidade e melhor 


\section{RECIMA21 - REVISTA CIENTÍFICA MULTIDISCIPLINAR}

ETNOASTRONOMIA E ASTROBIOLOGIA CULTURAL: ICONOGRAFIA ZOOMÓRFICA

DAS CONSTELACÕES INDÍGENAS BRASILEIRAS

Amanda Hellen Sales Gonçalves, Bruno Leonardo do Nascimento Dias, Francielle Maria Antonio Silva

compreensão dos resultados, os dados foram separados por seções (Mastozoologia, Herpetologia, Entomologia e Ornitologia) de constelações.

\section{Resultados e discussão}

A maioria dos povos antigos quando deixou de ser nômade para ter uma aldeia fixa precisou criar um calendário. A maneira que eles encontraram para fazer essa marcação foi por meio do sol, da lua e também das constelações. De acordo com LIMA e MOREIRA (2005), já por volta de 1614, todos os tupinambás do Maranhão sabiam entender a relação do céu com a terra e utilizavam as estrelas como uma espécie de agenda do clima e como bússola para orientação.

Conforme AFONSO (2013), com base nas flutuações sazonais indicadas pelas constelações os povos indígenas brasileiros demarcavam o período da pesca, caça, plantio e colheita. Cada imagem formada no céu permitia aos índios identificar uma nova estação do ano que estava por vir. No entanto, vale destacar que a interpretação do céu à noite é diferente para cada povo, tal como já foi mencionado e isto muda de uma etnia para outra e depende da cultura e do ambiente ao redor. Uma tribo na Amazônia, por exemplo, pode ver uma constelação que não é possível visualizar no sul do país na mesma posição ou na mesma época do ano (AFONSO 2010).

\section{Constelações indígenas relacionadas à Mastozoologia}

\section{- Constelação do Cervo}

Segundo AFONSO (2009), a constelação do Cervo Blastocerus Wagner, 1844 (Artiodactyla: Cervidae), marca a chegada do Equinócio de Outono no Hemisfério Sul, quando seu desenho representado na Figura 1 se encontra completamente visível no céu. Ainda conforme o autor o aparecimento dessa constelação para os povos Guarani é uma passagem entre o calor e o frio, que se estende até a primavera. Este período era conhecido pelos índios como "Tempo Velho". Em contrapartida, para os índios do Norte esse processo significa uma estação que marca a passagem entre a seca e a chuva, sendo característica da segunda quinzena de março. 


\section{RECIMA21 - REVISTA CIENTÍFICA MULTIDISCIPLINAR}

ETNOASTRONOMIA E ASTROBIOLOGIA CULTURAL: ICONOGRAFIA ZOOMÓRFICA

DAS CONSTELACÕES INDÍGENAS BRASILEIRAS Amanda Hellen Sales Gonçalves, Bruno Leonardo do Nascimento Dias, Francielle Maria Antonio Silva

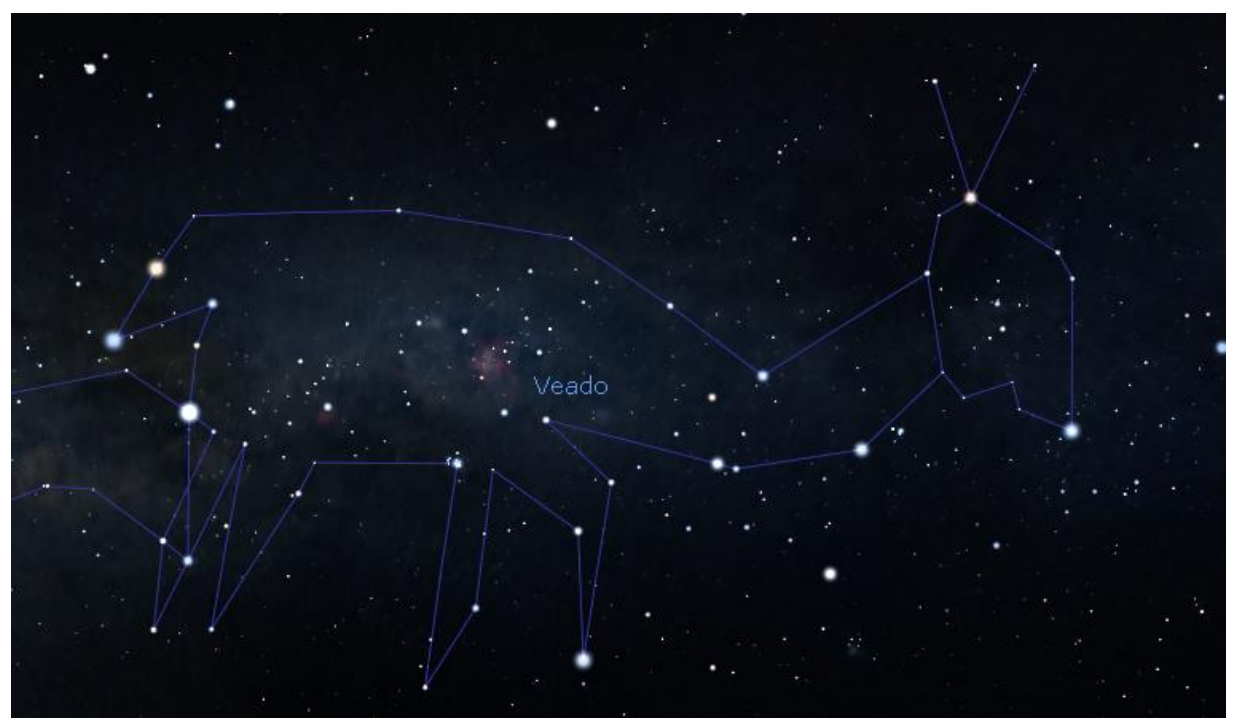

Figura 1 - Constelação do Cervo com representação obtida através do software Stellarium.

É interessante frisar que as estrelas que a compõem a constelação do cervo, incluem as conhecidas constelações do Cruzeiro do Sul e a Falsa Cruz, tal como algumas estrelas das constelações Carina, Vela e Centaurus (AFONSO, 2013; LIMA e MOREIRA, 2005). Na Figura 2 é possível ver as configurações mencionadas relativas às constelações do Cruzeiro do Sul, Carina, Vela e Centaurus.

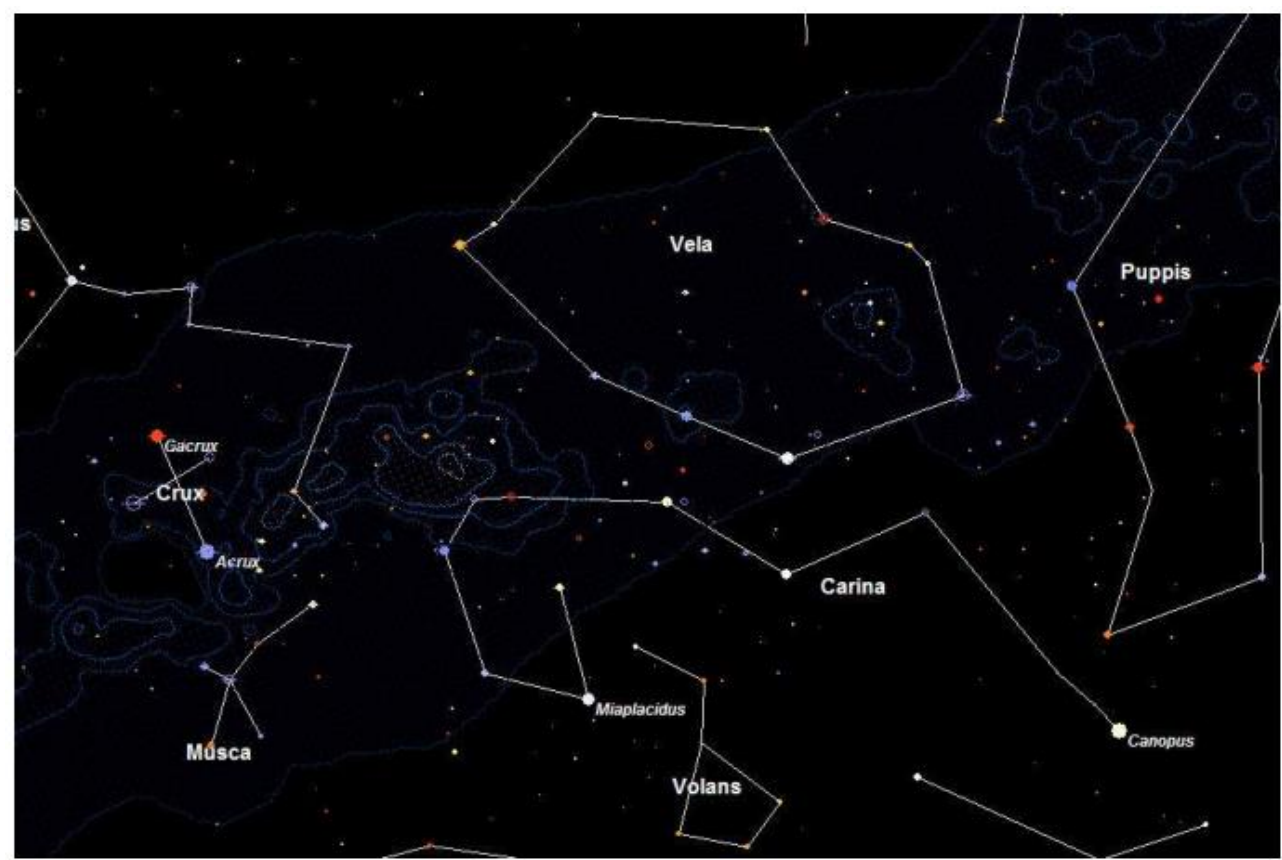




\section{RECIMA21 - REVISTA CIENTÍFICA MULTIDISCIPLINAR}

ETNOASTRONOMIA E ASTROBIOLOGIA CULTURAL: ICONOGRAFIA ZOOMÓRFICA

DAS CONSTELACÕES INDÍGENAS BRASILEIRAS Amanda Hellen Sales Gonçalves, Bruno Leonardo do Nascimento Dias, Francielle Maria Antonio Silva

Figura 2 - Grupo de constelações ocidentais que compõem a Constelação do Cervo. Fonte: AFONSO (2013).

\section{- Constelação da onça}

Para os povos indígenas a constelação da onça Panthera onca Linnaeus, 1758 (Carnivora: Felidae) possuía ligação com o ciclo das águas. Para os povos Tukano, por exemplo, que vivem na região amazônica do Alto Rio Negro, entre Brasil e Colômbia, o rugido da onça é associado ao trovão e ao relâmpago, forças fertilizadoras (SAUNDERS, 1998). Entre os Ticuna, povo que vive na fronteira entre Brasil e Peru, na Amazônia, a ascensão e o declínio da constelação da onça na Figura 3 marca a chegada e o fim da estação das chuvas (FAULHABER, 2004).

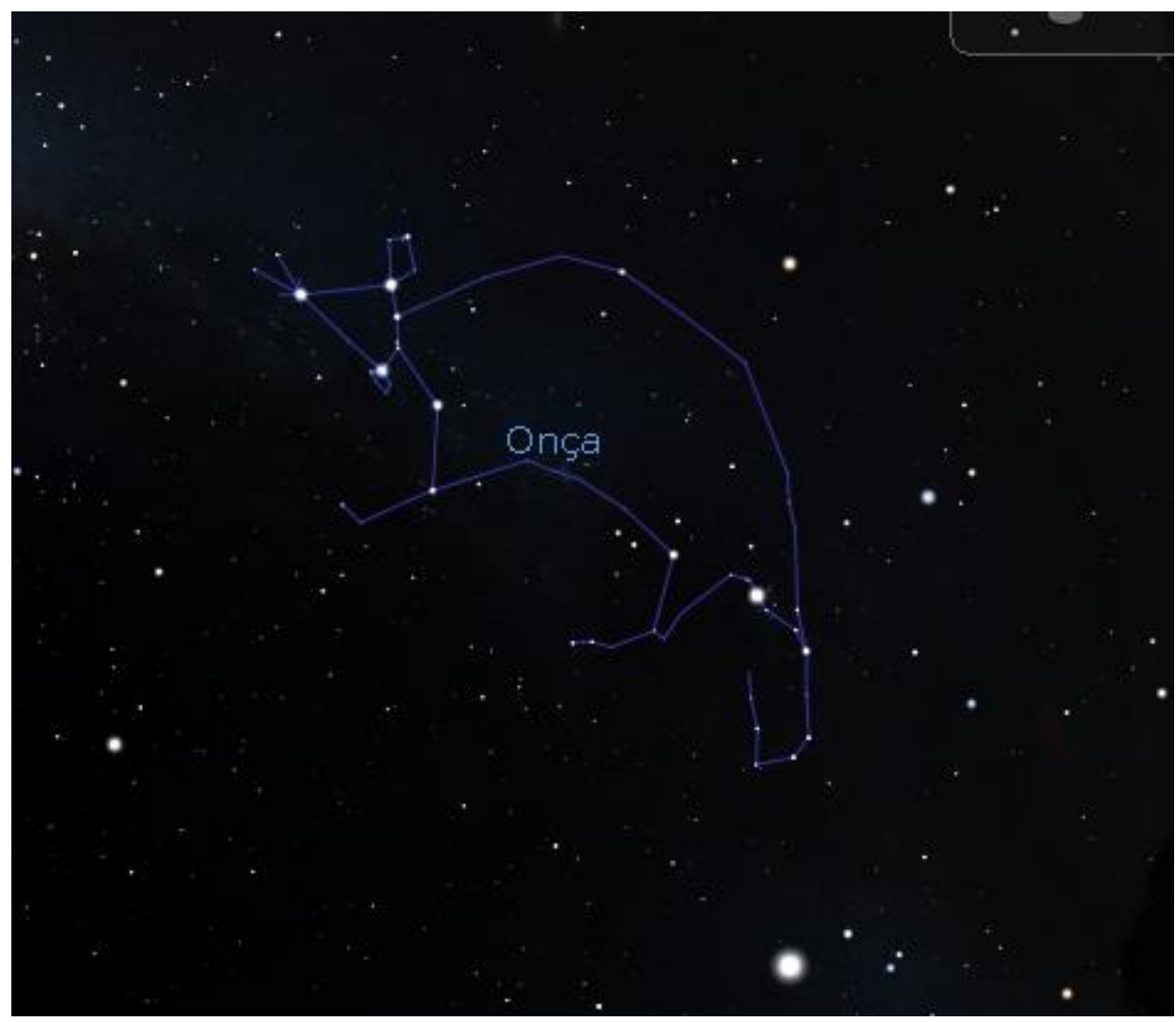

Figura 3 - Constelação da onça com representação obtida através do software Stellarium.

Conforme FAULHABER (2004), a constelação da Onça (Yai no idioma Tukano) está dividida em cinco pequenas constelações, que seriam Yai siõkhã (estrela que ilumina a onça), Yai useka poari (bigode), Yai duhpoa (cabeça da onça), Yai ohpu (corpo) e Yai pihkorõ (rabo). A constelação Yai fica na região do céu onde encontra-se as constelação de Cassiopéia, Andrômeda e Perseus. 


\section{RECIMA21 - REVISTA CIENTÍFICA MULTIDISCIPLINAR}

ETNOASTRONOMIA E ASTROBIOLOGIA CULTURAL: ICONOGRAFIA ZOOMÓRFICA

DAS CONSTELACÕES INDÍGENAS BRASILEIRAS Amanda Hellen Sales Gonçalves, Bruno Leonardo do Nascimento Dias, Francielle Maria Antonio Silva

- Constelação da Anta

A constelação da Anta Tapirus terrestris Linnaeus, 1758 (Perissodactyla: Tapiridae) também chamada de constelação de Tapi'i é a figura de uma anta que percorre a Via Láctea, chamado pelos índios de Caminho das Antas. De acordo com AFONSO (2013) a constelação da Anta do Norte na Figura 4 é conhecida principalmente pelas etnias de índios brasileiros que habitam na região norte do Brasil, tendo em vista que para as etnias da região sul ela fica muito próxima da linha do horizonte. Ela fica totalmente na Via Láctea, que participa muito nas definições de seu contorno, fornecendo uma imagem impressionante dessa constelação.

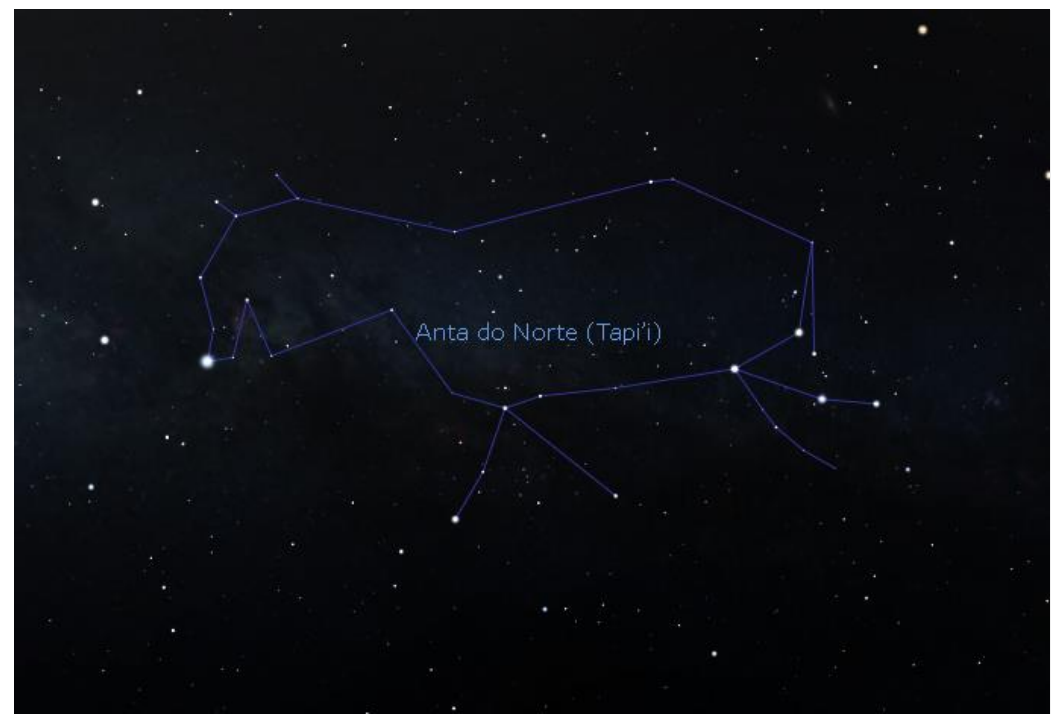

Figura 4 - Constelação da anta do Norte com representação obtida através do software Stellarium.

Para os índios do Norte, a anta do Norte anuncia a chegada da primavera surgindo na segunda quinzena de setembro. Além disso, essa constelação marca a transição entre a seca e a chuva. No entanto, para os Índios do Sul indica a transição entre o frio e o calor e por conta da difícil observação da Anta, o Sul utiliza a constelação do Colibri para indicar a chegada da primavera (AFONSO, 2013; LIMA e MOREIRA, 2005).

\section{Constelações indígenas relacionadas à Ornitologia}

- Constelação do Colibri ou Beija-Flor

De acordo com a lenda, Mainamy o chefe dos Beija-Flores Colibri Spix, 1824, (Apodiformes: Trochilidae) vem de um lugar bastante seco, onde não existia água, chamado Karu-Peahary. Então, 


\section{RECIMA21 - REVISTA CIENTÍFICA MULTIDISCIPLINAR}

ETNOASTRONOMIA E ASTROBIOLOGIA CULTURAL: ICONOGRAFIA ZOOMÓRFICA DAS CONSTELACÕES INDÍGENAS BRASILEIRAS Amanda Hellen Sales Gonçalves, Bruno Leonardo do Nascimento Dias, Francielle Maria Antonio Silva

a deusa Maíra construiu um poço para satisfazer a sede de Mainamy. A constelação do Beija-Flor na Figura 5 se encontra entre o Norte e o Sul, na mesma região que conhecemos como a constelação do Corvo. Para o povo Tembé a chegada da constelação é marcada com a festa da moça que é um ritual de passagem dos jovens índios para a vida adulta.

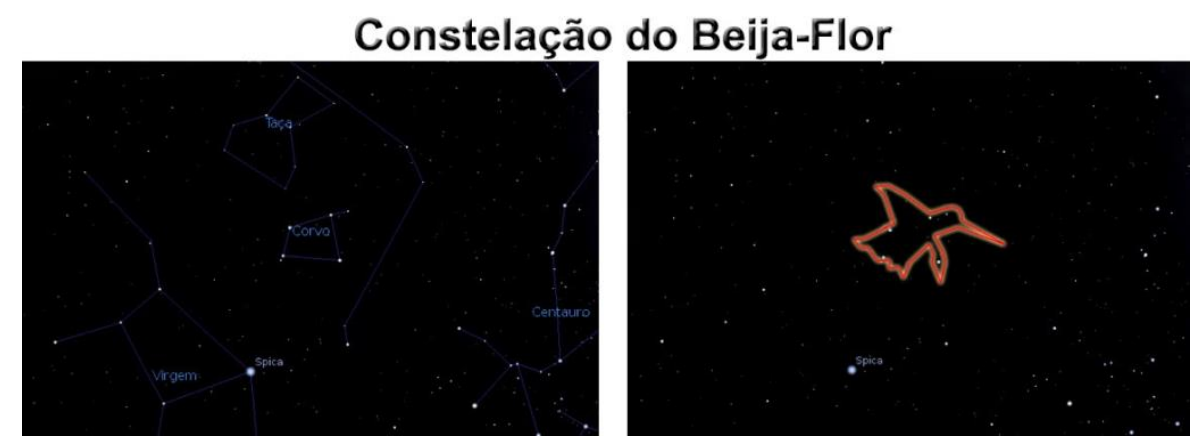

Figura 5 - Constelação do Beija-Flor. Fonte: AFONSO (2013)

\section{- Constelação do Corvo}

Segundo as lendas indígenas esta constelação aparece no tempo das chuvas. Na Figura 6 a constelação do corvo Corvus corax Linnaeus, 1758 (Corvidae: Corvus) é apresentada composta por cinco estrelas.

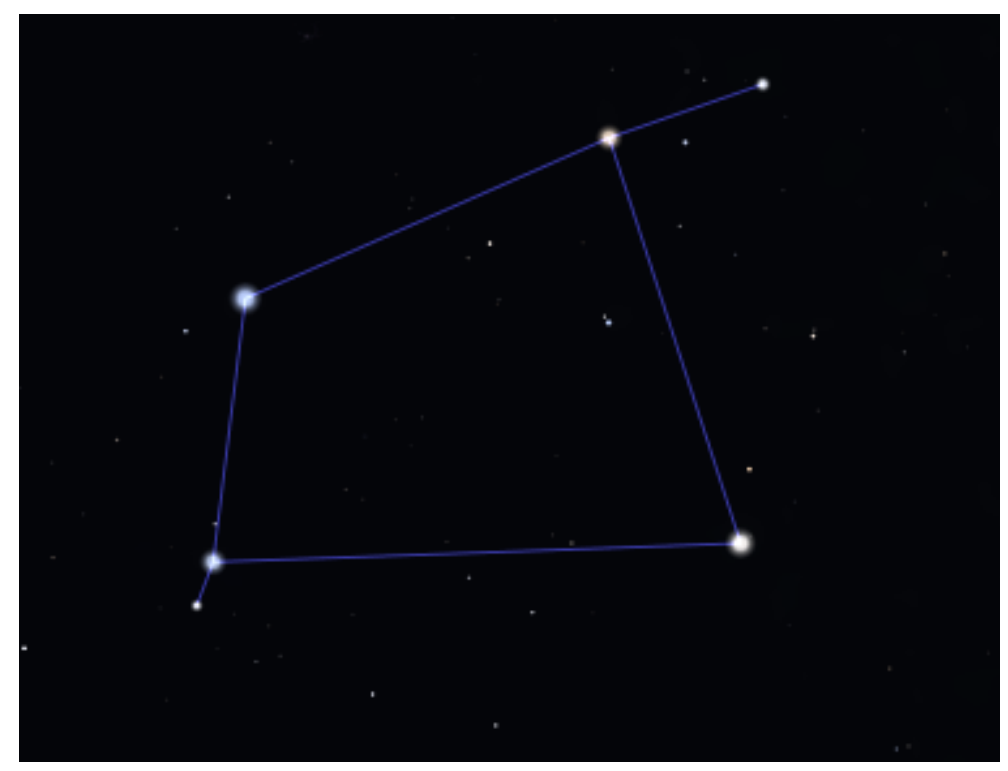

Figura 6 - Constelação do Corvo com representação obtida através do software Stellarium.

Sua origem vem da composição Uru (Ave, galinácio) e Bu (Negro); caraterizando o corvo. Essa constelação, segundo AFONSO (2010), está intimamente ligada à constelação do Beija-Flor, porque ela se encontra no poço onde o beija-flor bebe água. 


\section{RECIMA21 - REVISTA CIENTÍFICA MULTIDISCIPLINAR}

ETNOASTRONOMIA E ASTROBIOLOGIA CULTURAL: ICONOGRAFIA ZOOMÓRFICA

DAS CONSTELACÕES INDÍGENAS BRASILEIRAS Amanda Hellen Sales Gonçalves, Bruno Leonardo do Nascimento Dias, Francielle Maria Antonio Silva

\section{- Constelação da Ema}

Conforme as lendas indígenas a constelação da Ema Rhea americana Linnaeus, 1758 (Rheidae: Rhea) representa uma devoradora de ovos, que tenta a todo custo devorar Guirá-Rupiá (os dois ovos de pássaro, em Guarani) que ficam perto de seu bico. Sua plumagem é composta das manchas claras e escuras da Via Láctea.

A constelação da Ema (Wiranu, em Guarani) na Figura 7 também é chamada de Avestruz Branca. De acordo com AFONSO (2013), na segunda quinzena de junho, o início do inverno para os índios do sul do Brasil é indicado quando a Ema (Guirá Nhandu, em Guarani) surge totalmente ao anoitecer no lado leste. Em contrapartida, para os índios do norte do Brasil esse acontecimento indica o início da estação seca.

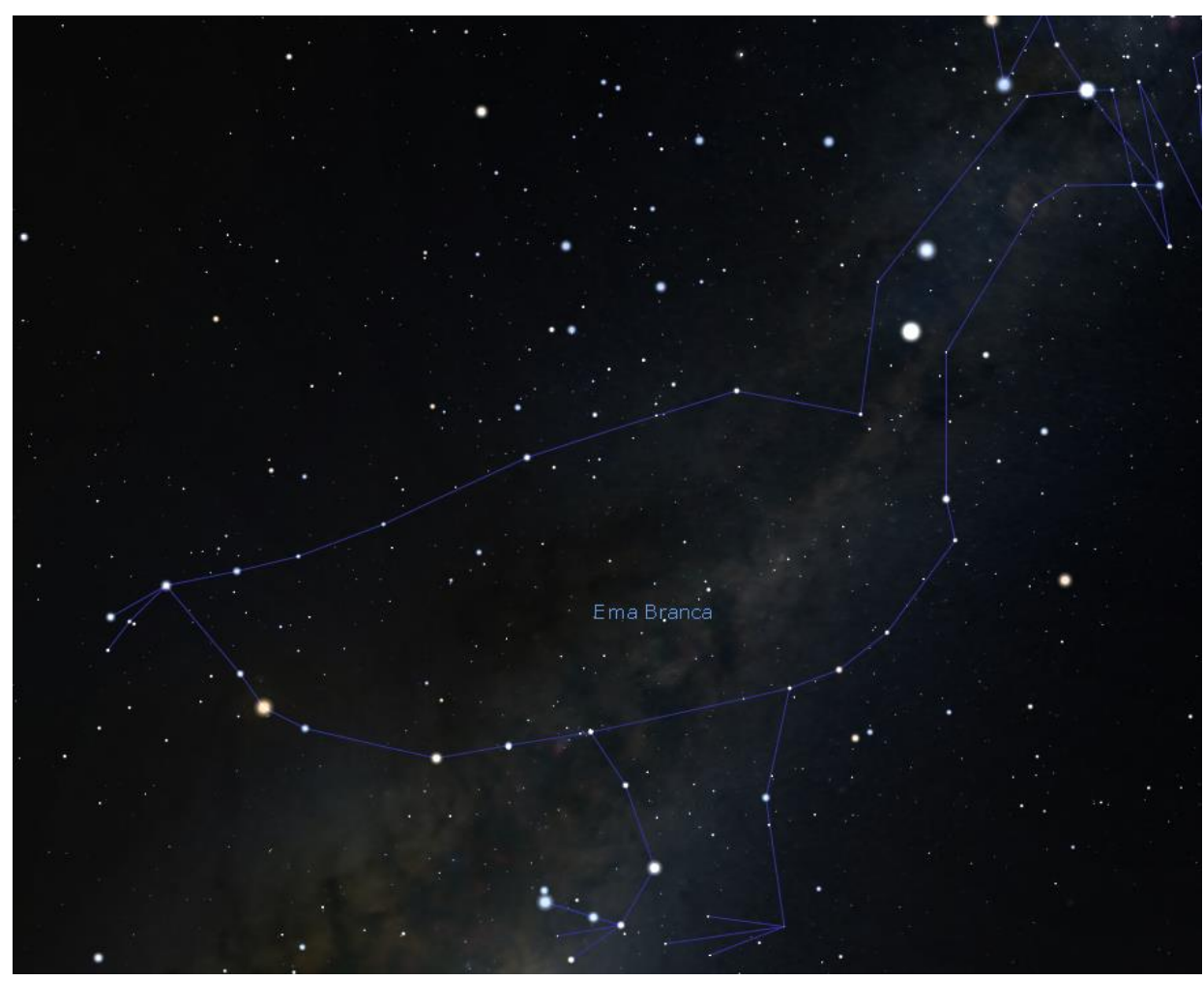

Figura 7 - Constelação da Ema com representação obtida através do software Stellarium.

Ainda segundo AFONSO (2013), o escritor d'Abbeville em seu livro menciona que a constelação da Ema descrita pelos índios brasileiros é formada por estrelas muito grandes e brilhantes. A constelação da Ema fica na região do céu limitada pelas constelações ocidentais Crux e Scorpius (AFONSO, 2010 e LIMA e MOREIRA 2005).

- Constelação da Siriema 


\section{RECIMA21 - REVISTA CIENTÍFICA MULTIDISCIPLINAR}

ETNOASTRONOMIA E ASTROBIOLOGIA CULTURAL: ICONOGRAFIA ZOOMÓRFICA

DAS CONSTELACÕES INDÍGENAS BRASILEIRAS Amanda Hellen Sales Gonçalves, Bruno Leonardo do Nascimento Dias, Francielle Maria Antonio Silva

A Constelação da Siriema Cariamidae Bonaparte, 1853 (está intimamente ligada à constelação da Ema, localizando-se abaixo dela onde encontramos as constelações ocidentais Coroa Austral, Telescópio, Sagitário e Escorpião. Na Figura 8 é apresentada a constelação da Siriema, que é chamada assim por conta de suas diversas partes serem constituídas de manchas da via láctea.

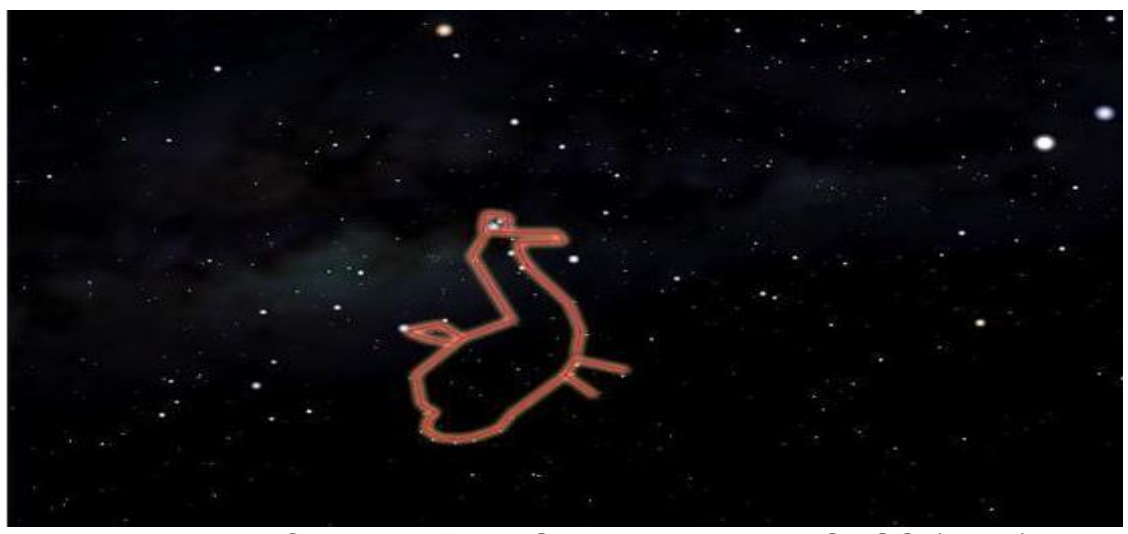

Figura 8 - Constelação da Siriema. Fonte: AFONSO (2013)

Ela indica o início da estação da seca, no mês de junho e julho. Na astronomia indígena, os desenhos que formam as imagens das constelações muitas das vezes abrangem essas manchas encontradas na via láctea. "A Siriema possui um penacho em sua cabeça, e os índios Tembé dizem que na constelação, a Siriema carrega seus dois ovinhos para que a Ema, a comedora de ovos, não os devore."

\section{- Constelação da Graça}

A constelação da Garça Ardea Linnaeus, 1758 (Ardeidae) na Figura 9, foi criada pelos Pamuri Mahsa que usavam as plumas (Uga, na língua indígena) da Garça (Yhé, na língua indígena) para enfeite de festivais nas aldeias, estão associadas à Via Láctea. (DESANA, 2019). O símbolo da garça a ocupa a região da constelação ocidental da cabeleira da Berenice. 


\section{RECIMA21 - REVISTA CIENTÍFICA MULTIDISCIPLINAR}

ETNOASTRONOMIA E ASTROBIOLOGIA CULTURAL: ICONOGRAFIA ZOOMÓRFICA

DAS CONSTELACÕES INDÍGENAS BRASILEIRAS Amanda Hellen Sales Gonçalves, Bruno Leonardo do Nascimento Dias, Francielle Maria Antonio Silva

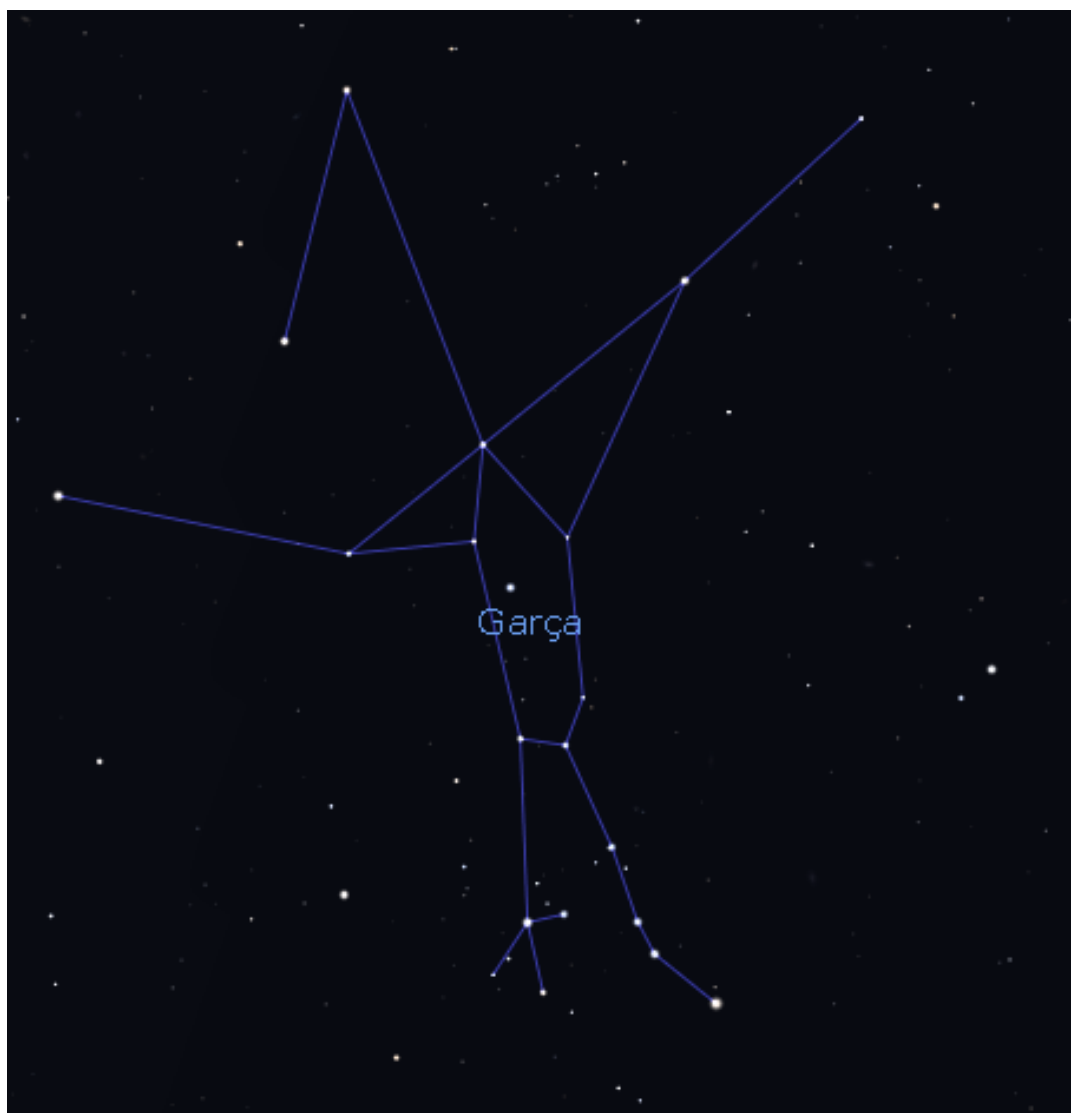

Figura 9 - Constelação da Garça com representação obtida através do software Stellarium.

Segundo a lenda, os índios mataram a Garça de Abiu, conhecida como Rei das Garças, por ser considerada a mais bonita dentre todas as aves (HUGH-JONES, 2017). Porém, se arrependeram por tê-la matado, então, fizeram o corpo dela ficar bem no centro do universo para recordar o fato de que era o Rei das Garças. De acordo com CARDOSO (2020), a constelação da garça parecia mediar entre as duas metades da Via Láctea e, assim, manter sua continuidade. De acordo com HUGHJONES, (2017), a constelação Yhé anuncia a dificuldade para a obtenção de peixes. Essa constelação faz referência a constelação de Virgem.

\section{- Constelação do Tinguaçu}

A constelação do Tinguaçu Piaya cayana Linnaeus, 1766 (Cuculiformes: Cuculidae) na Figura 10, de acordo com DA FONSECA et al. (2007), ocupa uma região entre Touro, Áries e Perseu. O corpo da ave aloca-se na constelação de Touro. No caso do pescoço, da cabeça e do bico é possível localizar na região de Áries. Por fim, os pés ficam na região de Perseu e a cauda nas Híades. Por se tratar de uma constelação, em que sua configuração estrutural possui como uma de suas partes a constelação de Touro, também é conhecida como mensageira das Plêiades, as quais são responsáveis por anunciar o seu aparecimento nos céus. 


\section{RECIMA21 - REVISTA CIENTÍFICA MULTIDISCIPLINAR}

ETNOASTRONOMIA E ASTROBIOLOGIA CULTURAL: ICONOGRAFIA ZOOMÓRFICA

DAS CONSTELACÕES INDÍGENAS BRASILEIRAS Amanda Hellen Sales Gonçalves, Bruno Leonardo do Nascimento Dias, Francielle Maria Antonio Silva

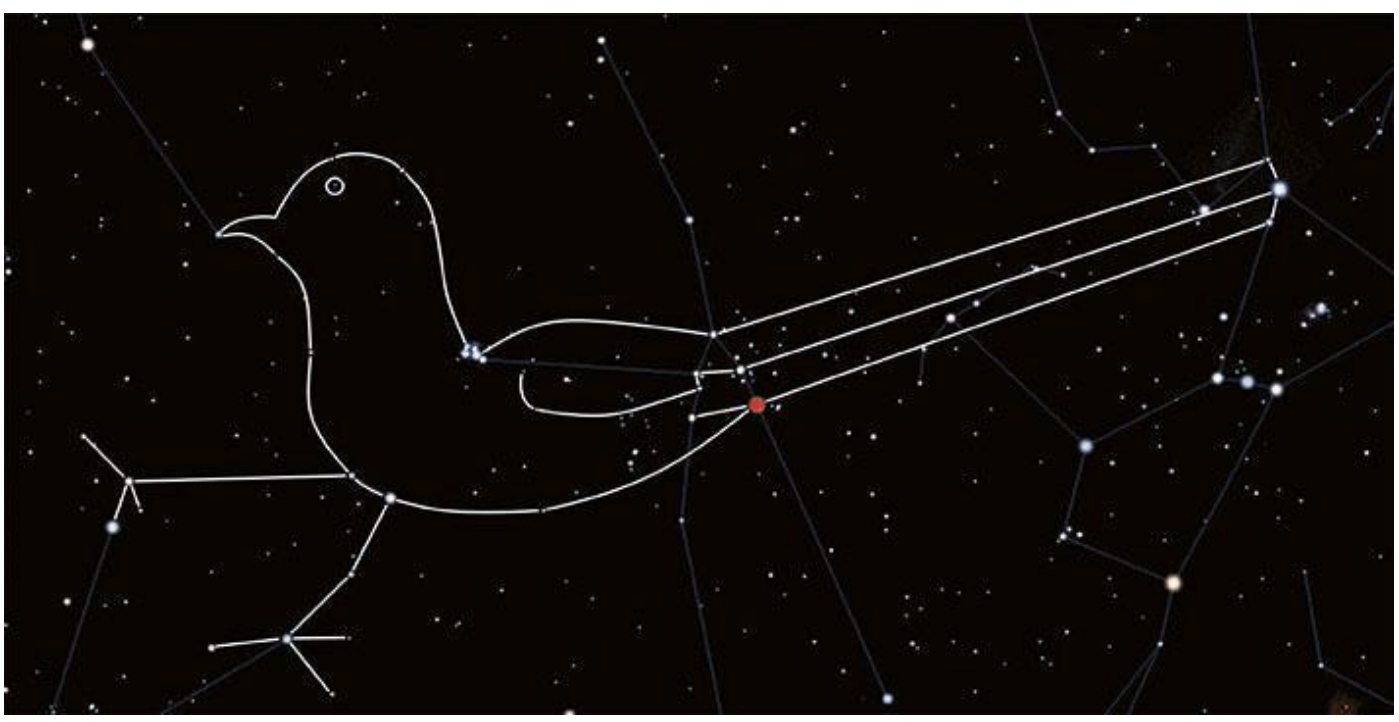

Figura 10 - Constelação do Tinguaçu. Fonte: Cid Marcus, 2017.

\section{Constelações indígenas relacionadas à Entomologia}

\section{- Constelação das Abelhas ou colmeia}

Essa constelação tem nomes diferentes nos povos Tupi-Guarani, Eixu significa "Colmeia ou ninho de abelhas" (Anthophila: Hymenoptera) em guarani e para o povo Tupi Seichu "vespeiro" (Figura 11). É composta por um aglomerado de estrelas jovens, azuis, que se localizam na constelação ocidental do Touro. Com a luz natural e a olho nu é possível observar sete dessas estrelas e, por isso, como as sete estrelas ou as sete irmãs. 


\section{RECIMA21 - REVISTA CIENTÍFICA MULTIDISCIPLINAR}

ETNOASTRONOMIA E ASTROBIOLOGIA CULTURAL: ICONOGRAFIA ZOOMÓRFICA

DAS CONSTELACÕES INDÍGENAS BRASILEIRAS Amanda Hellen Sales Gonçalves, Bruno Leonardo do Nascimento Dias, Francielle Maria Antonio Silva

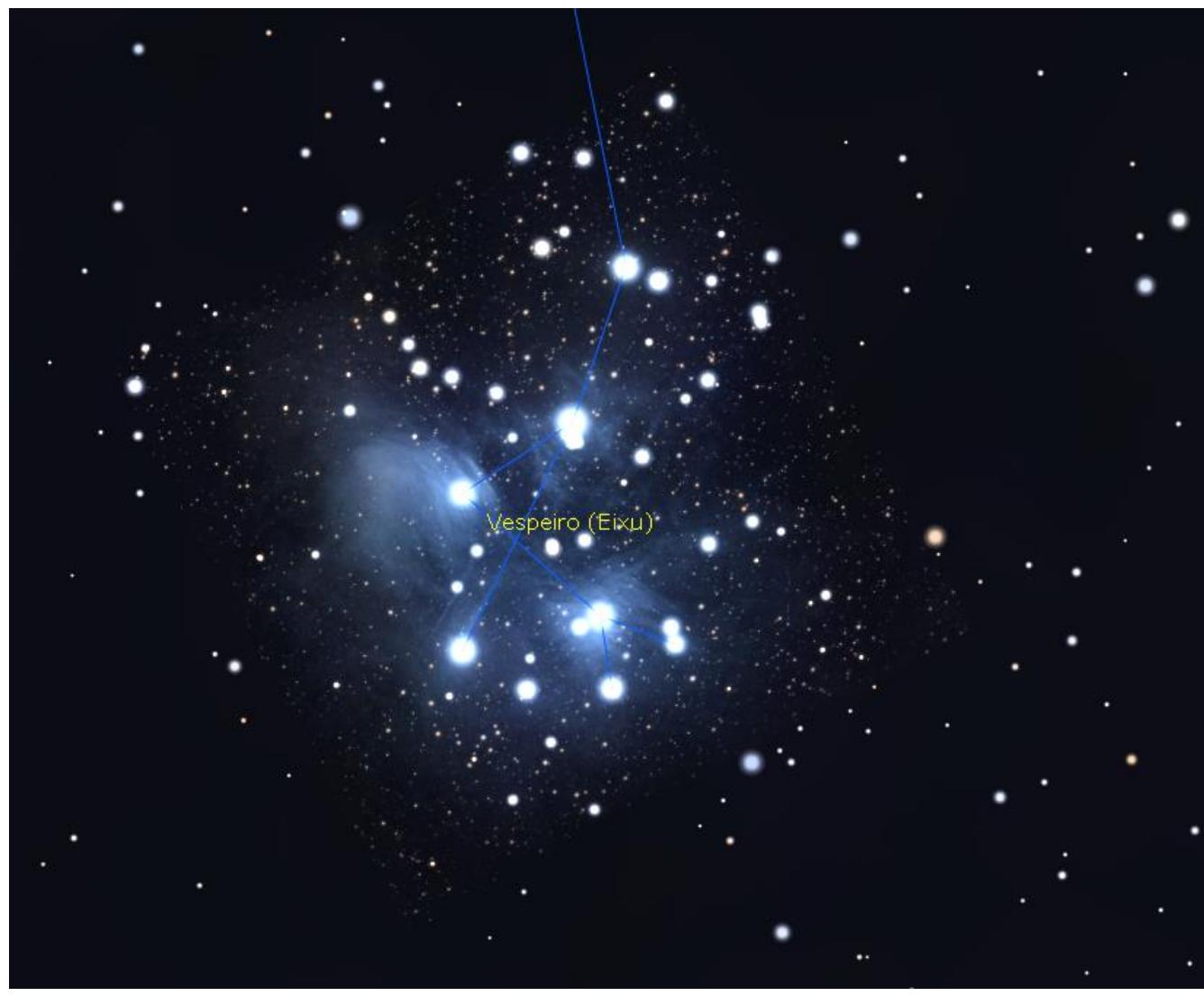

Figura 11 - Região da constelação das abelhas com representação obtida através do software Stellarium.

Conforme AFONSO (2013), o francês D'Abbeville diz: "Temos entre nós a 'Poussinière' (Plêiades) as que muito bem conhecem e que denominam seichu. Começa a ser vista, em seu hemisfério, em meados de janeiro, e mal a enxergam afirmam que as chuvas vão chegar, como chegam efetivamente pouco depois". Ainda segundo AFONSO (2013), essa constelação marca o início do ano, quando surge pela primeira vez no lado leste, antes do nascer do Sol (Nascer Helíaco das Plêiades), na primeira quinzena de junho. Com essa constelação que os índios faziam a contagem dos anos.

\section{Constelações indígenas relacionadas à Herpetologia}

- Constelação da cobra ou Jararaca

A constelação da Cobra Bothriopsis Peters, 1861 (Squamata:Viperidae) na Figura 12, se encontra na região do céu que conhecemos como constelação do Escorpião. No entanto, os índios não 


\section{RECIMA21 - REVISTA CIENTÍFICA MULTIDISCIPLINAR}

ETNOASTRONOMIA E ASTROBIOLOGIA CULTURAL: ICONOGRAFIA ZOOMÓRFICA

DAS CONSTELACÕES INDÍGENAS BRASILEIRAS Amanda Hellen Sales Gonçalves, Bruno Leonardo do Nascimento Dias, Francielle Maria Antonio Silva

consideraram as garras do escorpião (AFONSO 2009). A estrela Antares simboliza a cabeça da cobra.

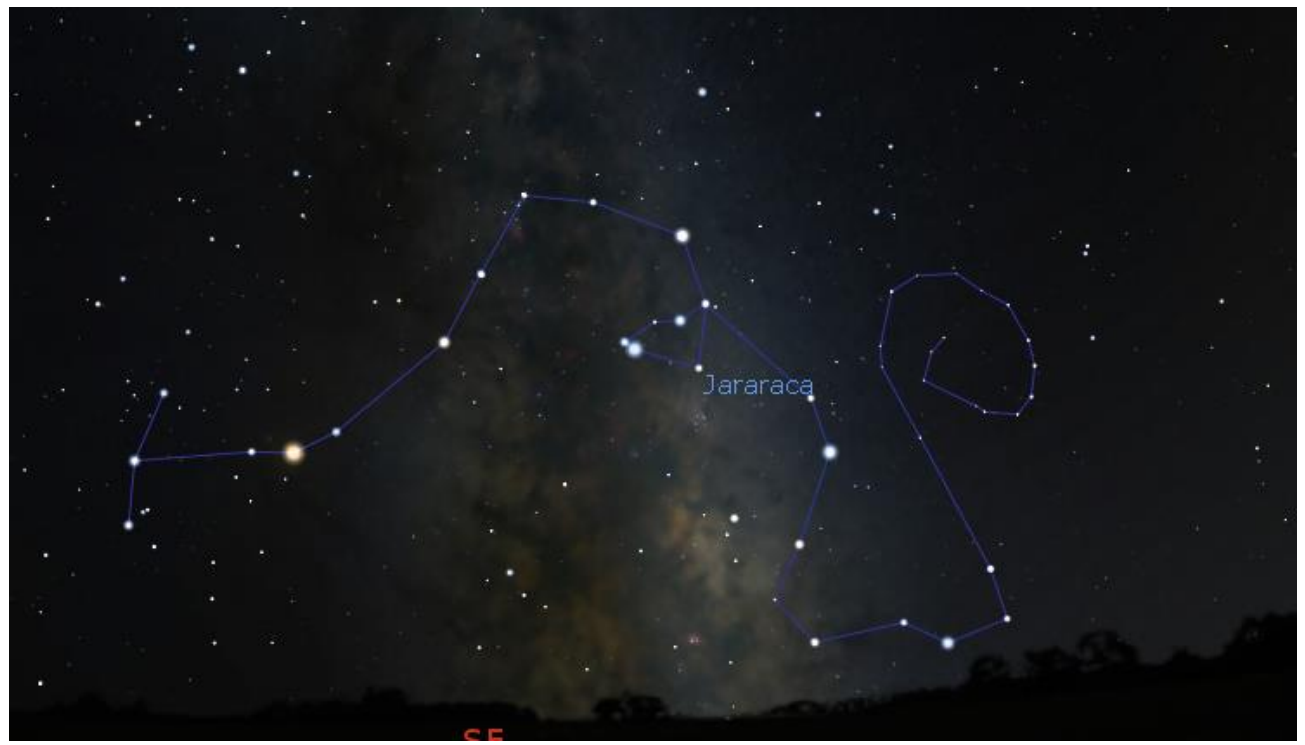

Figura 12 - Constelação da cobra com representação obtida através do software Stellarium.

A constelação da cobra (Mboi, na língua indígena) é associada pelos Tukano, índios do Norte do Brasil, com o período das chuvas. Conforme AFONSO (2009), eles fazem essa associação porque durante as cheias do rio, a jararaca chega às aldeias. Essa constelação é formada por: Aña duhpoa (cabeça), Aña nimaga (bolsa de veneno), Aña ñemeturi (fígado), Aña dieripa (ovos), Aña ohpu (corpo) e Aña pihkorõ (rabo) e Aña siõkhã (estrela que ilumina a jararaca).

\section{- Constelação da Tartaruga e Jacaré}

De acordo com LIMA e MOREIRA (2005), a constelação da tartaruga Testudines Batsch, 1788 e a queixada do jacaré Alligatoridae Gray, 1844 são tratadas juntas (Figura 13), devido a compartilharem:

1. "O início das chuvas é anunciado pela ascenção de Baweta, que aparece no céu no início da noite, a Leste, no fim de novembro. Após subir Baweta, sobe a "Queixada do Jacaré". A 


\section{RECIMA21 - REVISTA CIENTÍFICA MULTIDISCIPLINAR}

ETNOASTRONOMIA E ASTROBIOLOGIA CULTURAL: ICONOGRAFIA ZOOMÓRFICA DAS CONSTELACÕES INDÍGENAS BRASILEIRAS Amanda Hellen Sales Gonçalves, Bruno Leonardo do Nascimento Dias, Francielle Maria Antonio Silva perna de Wü̈ütcha corresponde a Órion. Ela começa a desaparecer no céu, a Oeste, a partir de 20 de maio ao anoitecer."

2. "Baweta (coletivo de tartaruga) associa-se ao conjunto de estrelas das constelações convencionais das Plêiades e de Perseu, sendo seus olhos os pés de Perseu (Ômicron Persei e Atik). Supõe-se que a forma de $\mathrm{V}$, que para a astronomia ocidental está relacionada com as Híades, no vértice da cabeça do Touro, recebe pelos Ticuna o nome de Coyatchicüra (Queixada do Jacaré) 11. Em um desenho Ticuna, a pata esquerda do Jacaré corresponde à estrela Euratis, e a pata traseira direita a e (epsílon), h (eta) e z (zeta). A cauda está em o (ômicrom) e z (zeta), de Perseu."

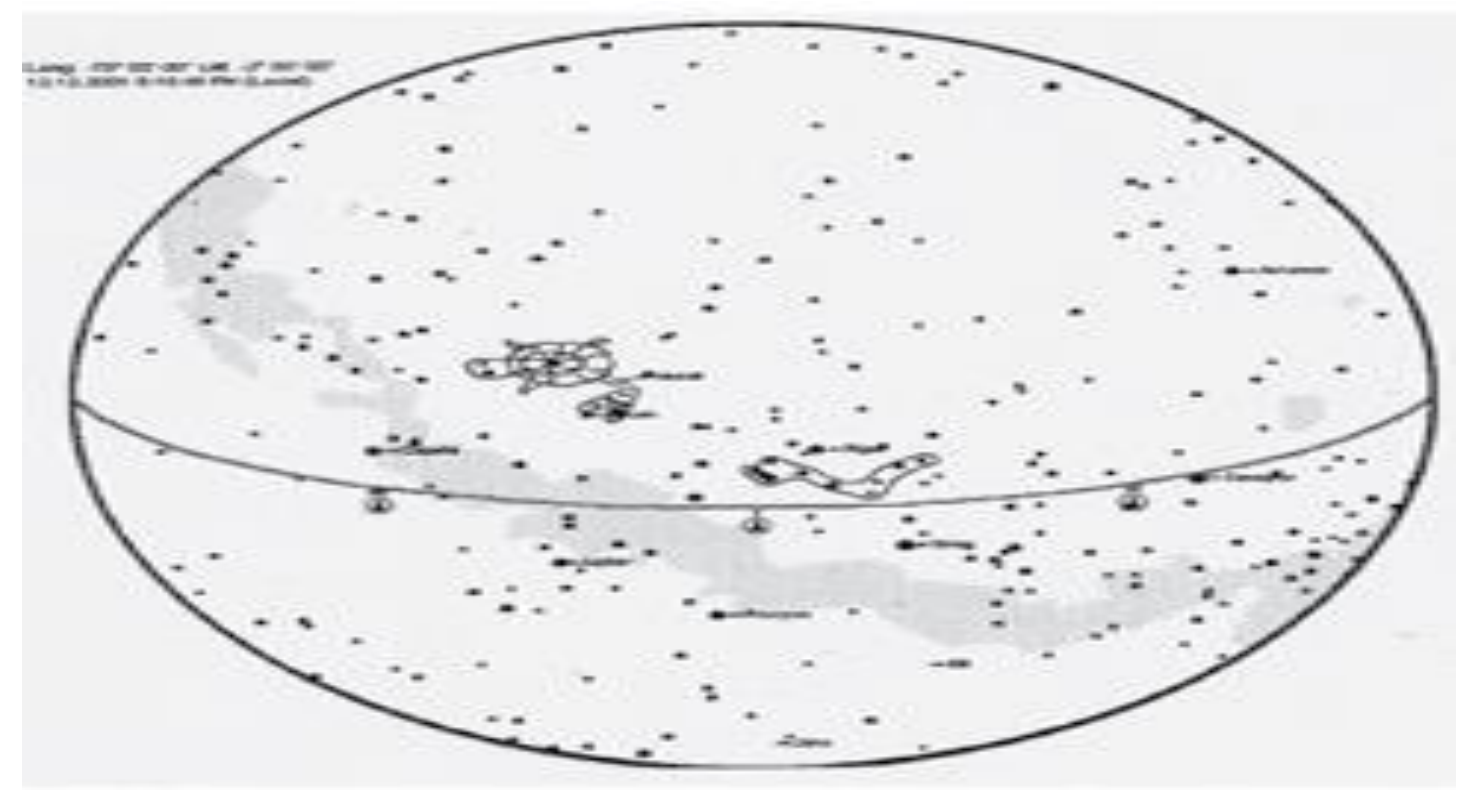

Figura 13 - Constelações da tartaruga e da queixada de jacaré. Fonte: FAULHABER (2004).

\section{- Constelação do Jabuti}

"A constelação do Jabuti C. carbonariase encontra no lado norte do céu ocupando a região que conhecemos como Coroa Boreal. O Jabuti (lawoti em Tupi) e (Zauxihu Ragapaw, em Guarani), conforme AFONSO (2013), significa que os índios estão enfrentando o final da época das chuvas. Esse período é marcado pela presença da constelação do jabuti que vai percorrendo o céu noturno, entre maio e agosto. 


\section{RECIMA21 - REVISTA CIENTÍFICA MULTIDISCIPLINAR}

ETNOASTRONOMIA E ASTROBIOLOGIA CULTURAL: ICONOGRAFIA ZOOMÓRFICA

DAS CONSTELACÕES INDÍGENAS BRASILEIRAS Amanda Hellen Sales Gonçalves, Bruno Leonardo do Nascimento Dias, Francielle Maria Antonio Silva

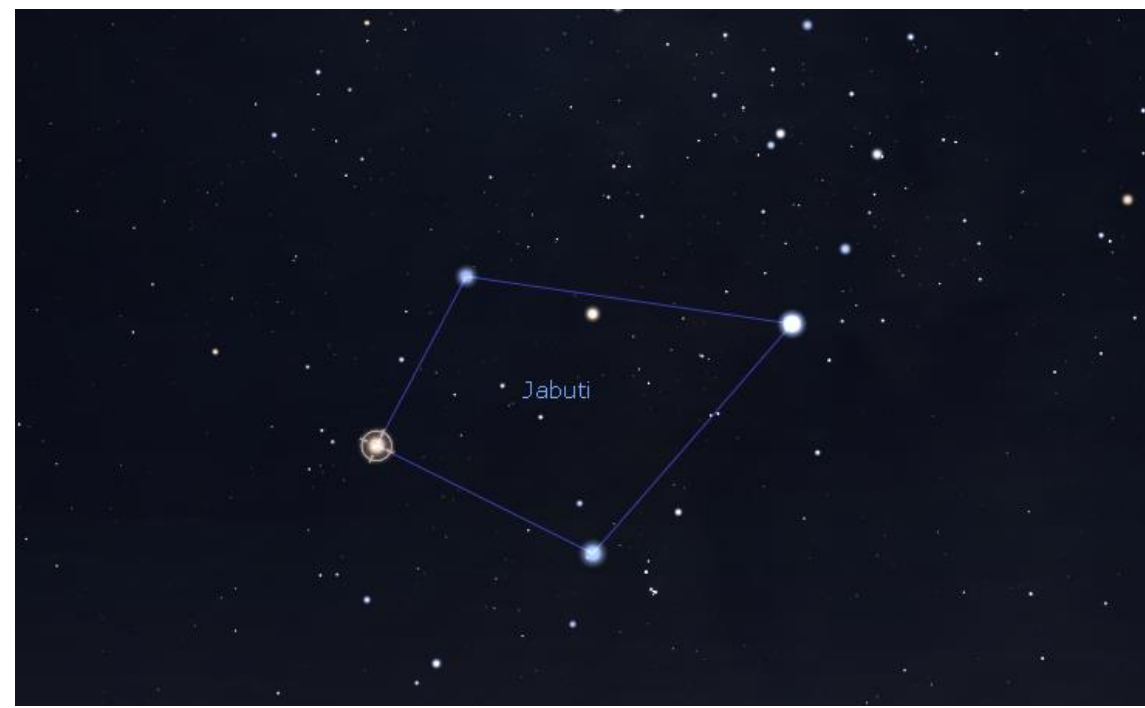

Figura 14 - Constelação do Jabuti com representação obtida através do software Stellarium.

\section{Considerações finais}

Com base nos resultados foi possível concluir que, tal como ocorre com a Astronomia ocidental, a Astronomia indígena também possui conotações e detalhamentos riquíssimos relacionados a cultura e a natureza regional. Também é possível constatar que a ideia de natureza/ambiente entre os povos indígenas brasileiros é multidimensional e se configura como o mundo do qual se faz parte.

Durante o decorrer do texto não houve a distinção entre as constelações Tupis e as Guaranis, pois curiosamente ambas são muito semelhantes aquelas. Vale salientar que os índios Tupinambás (norte do Brasil) e os índios Guaranis (sul do Brasil), eram separados por quase $3 \mathrm{mil} \mathrm{km} \mathrm{em} \mathrm{linha}$ reta, por línguas (Tupi e Guarani) e mais espectacular ainda, pelo tempo em cerca de 400 anos de diferença. Ademais, outro fato ainda mais intrigante observado durante a coleta de dados, é que algumas constelações dos índios brasileiros eram as mesmas de outros índios da América do Sul, e até mesmo dos aborígenes australianos.

Os estudos historiográficos dentre os artigos usados como base para a formação deste artigo, mostra que os índios brasileiros dão grande valor à região da Via Láctea. Esta perspectiva fica evidente ao constatar ao longo das inúmeras constelações presente neste texto, que suas principais constelações se localizavam ao longo ou adjacências da Via Láctea (caminho do leite na cultura grega e caminho das antas na cultura indígena) que eram constituídas de estrelas e até nebulosas, principalmente às escuras. 


\title{
RECIMA21 - REVISTA CIENTÍFICA MULTIDISCIPLINAR
}

\author{
ETNOASTRONOMIA E ASTROBIOLOGIA CULTURAL: ICONOGRAFIA ZOOMÓRFICA \\ DAS CONSTELACÕES INDÍGENAS BRASILEIRAS \\ Amanda Hellen Sales Gonçalves, Bruno Leonardo do Nascimento Dias, Francielle Maria Antonio Silva
}

Algumas constelações se mantiveram fora das apresentações dos resultados obtidos, pois em diversos artigos, apesar de serem mencionadas não eram bem identificadas até hoje. Dentre essas constelações podem ser elencadas a do pássaro Bihpia, a (s) lontra (s) Dia yó (a), ñamia que se constitui num conjunto de formigas que boiam assim como yaká, o peixe cascudo. Acredita-se que grande parte dessas constelações estejam dentro da Via Láctea, justo por causa das imagens que elas nos remetem, como folhas secas e formigas que boiam. Assim, por conta da poluição luminosa existente nos dias atuais é praticamente impossível detectar essas constelações que dependeriam da grande de estrelas reunidas para gerarem a quantidade necessária de elementos como folhas e formigas podem estar associadas com essa região do céu.

Vale salientar que trabalhos etnográficos e interdisciplinares como esse tem a capacidade de despertar a curiosidade sobre a astronomia indígena, assim como toda a rica cultura nacional que pelos brasileiros é pouco conhecida. Os resultados alcançados demonstraram a potencialidade da abordagem do tema, inclusive no âmbito escolar, seja em unidades indígenas ou não-indígenas. Por fim, quando houver respeito, valorização e preservação da identidade cultural dos povos indígenas poderá se difundir, e a mitologia brasileira poderá se popularizar e não desaparecer. A cultura brasileira oriunda dos primeiros povos deste país é valiosa para o modo de vida, as visões de mundo e os rituais importantes da vida das pessoas e comunidades, não apenas indígenas, mas para todos os brasileiros.

\section{REFERÊNCIAS}

AFONSO, Germano Bruno. Astronomia indígena. Reunião anual da SBPC, v. 61, p. 1-5, 2009.

AFONSO, Germano Bruno. Astronomia Indígena. Revista de História, v. 1, p. 62-65, 2010.

AFONSO, Germano Bruno. As constelações indígenas brasileiras. Telescópios na Escola, Rio de Janeiro, p. 1-11, 2013.

CARDOSO, Walmir Thomazi. Constelações, enchentes, verões e invernos no Alto Rio Negro. Revista Cosmovisiones/Cosmovisões, v. 1, n. 1, p. 122-137, 2020.

CORREA, Luciana Flôr; SIMÕES, Bruno. Astronomia indígena na formação de professores: uma possibilidade a partir da abordagem CTS. Ciência e Natura, v. 38, n. 1, p. 475-483, 2016.

FONSECA, Omar Martins; PINTO, Simone Pinheiro; JURBERG, Claudia. Mitos e constelações indígenas, confeccionando um planetário de mão. Costa Rica: [s. e.]: 2007.

DESANO, Jaime Diakara. Wame: Gaapi, a bebida cósmica dos Desana. Mundo Amazónico, v. 10, n. 1, p. 13-37, 2019.

AMARAL FERREIRA, Marcelo Augusto; NADER, Rundsthen Vasques; BORGES, Luiz C. Astronomia cultural: diferentes culturas, diferentes céus. Revista Scientiarum História, v. 1, p. 7, 2019. 


\section{RECIMA21 - REVISTA CIENTÍFICA MULTIDISCIPLINAR}

ETNOASTRONOMIA E ASTROBIOLOGIA CULTURAL: ICONOGRAFIA ZOOMÓRFICA

DAS CONSTELACÕES INDÍGENAS BRASILEIRAS

Amanda Hellen Sales Gonçalves, Bruno Leonardo do Nascimento Dias, Francielle Maria Antonio Silva

FAULHABER, P. As estrelas eram terrenas: antropologia do clima, da iconogra!a e das constelações Ticuna. Revista de Antropologia, v. 47, n. 2, p. 379-426, 2004.

HUGH-JONES, Stephen. As Plêiades e Escorpião na Cosmologia Barasana. En Revista Anthropológicas. Ano, v. 21, n. 28, p. 1, 2017.

LIMA, Flávia Pedroza. Observações e descrições astronômicas de indígenas brasileiros: a visão dos missionários, colonizadores, viajantes e naturalistas. Revista da Sociedade Brasileira de História da Ciência, v. 2, n. 2, 2004.

LIMA, Flávia Pedroza; MOREIRA, I. C. Tradições astronômicas tupinambás na visão de Claude D’Abbeville. Revista da Sociedade Brasileira de História da Ciência, v. 3, n. 1, 2005.

MIRANDA, Leila Mourão. O viver e o fazer construindo mundos. Complexitas-Revista de Filosofia Temática, v. 2, n. 2, p. 74-94, 2019.

PEDRA, Graciele Macedo; CHAVES, Priscila Monteiro. Leitura das regionalidades culturais entre 0 pampa e o sertão na literatura brasileira. Caderno de Letras, n. 28, p. 75-89, 2017.

ROSSETTI, Regina. Aportes filosóficos ao estudo da globalização e regionalidade. Comunicação \& Inovação, v. 3, n. 6, 2003.

SAUNDERS, N. (Org.). Icons of power: feline symbolism in the Americas. London; New York: Routledge, 1998.

TOLMASQUIM, Alfredo Tiomno. As influências filosóficas na implantação da astronomia no Brasil: história da astronomia no Brasil. Recife: Companhia Editora de Pernambuco-Cepe, 2013. p. 520-542. 